\title{
Sustainable Beekeeping Cooperative Societies: The Case of Mexico City
}

\author{
Aida Huerta Barrientos", Alma E. Vera Morales, Laura P. Avila Callejas, Miguel A. Saldaña Cabrera, \\ Eduardo García López, Emiliano Gutiérrez Ayala
}

Department of Operations Research, Faculty of Engineering, UNAM, 04510, México.

\begin{abstract}
How to cite this paper: Aida Huerta Barrientos, Alma E. Vera Morales, Laura P. Avila Callejas, Miguel A. Saldaña Cabrera, Eduardo García López, Emiliano Gutiérrez Ayala. (2021) Sustainable Beekeeping Cooperative Societies: The Case of Mexico City. International Journal of the Science of Food and Agriculture, 5(1), 76-84. DOI: $10.26855 /$ ijfsa.2021.03.011
\end{abstract}

Received: December 27, 2020

Accepted: January 24, 2021

Published: February 5, 2021

*Corresponding author: Aida Huerta Barrientos, Department of Operations Research, Faculty of Engineering, UNAM, 04510, México.

Email: aida.huerta@comunidad.unam.mx

\begin{abstract}
Beekeeping is an activity of great relevance for natural ecosystems with social and economic dimensions. Unfortunately, the practice of beekeeping in Mexico City face challenges as following: the use of outdated technology that leads to low productivity, the poor organization for production and marketing that generates low economic profitability, the marketing controlled by the intermediary which eliminates the sustainable local value chain of honey in which local cooperatives societies participate. In this direction, the purpose of this chapter is to develop a model of socio-cultural innovation, which revalue the beekeeping of Mexico City as a traditional activity of ecological importance and improve its position as a sustainable productive activity of honey with the participation of local cooperatives societies. Firstly, we identify the beekeeping cooperative societies located in Mexico City. Secondly, we characterize the feasible opportunities of marketing of honey and its derivates in the context of Mexico City that leads to revalue the beekeeping as a traditional activity of ecological importance. Thirdly, we analyze the main characteristics of sustainable honey production models. Finally, we characterize a socio-cultural innovation model and integrate it to the cooperative business model for sustainable beekeeping. We consider that the main results of this study contribute to the sustainable development of beekeeping in Mexico City.
\end{abstract}

\section{Keywords}

Beekeeping, Mexico City, Innovation Process, Sustainability, Cooperative Societies

\section{Introduction}

Beekeeping is a sustainable production model crucial for biodiversity [1] with social and economic dimensions. It has been historically practiced in various places, included Mexico, as a part of the local food culture, as well as an activity related to the production of pollinators [2]. Nowadays, beekeeping is an important activity in Mexico with the food, economic, social, and ecological areas and has developed in different states along the country [3]. Based on the different climates and flora, which have the composition of nectar and pollen, Mexico is divided into five well-defined honey production regions: Altiplano, Costa del Pacífico, Golfo, Norte and Península de Yucatán. In 2017, there were 43,478 producers engaged in beekeeping nationwide who work with 1.853 million hives.

In Mexico City, there are almost 4,000 hives located in six municipalities: Alvaro Obregón, Magdalena Contreras, Milpa Alta, Tláhuac, Tlalpan y Xochimilco (see Figure 1). Unfortunately, the practice of beekeeping in Mexico City face challenges as following: the use of outdated technology that leads to low productivity (In the last decade, the honey production in Mexico City has been over 70 tons annually), the poor organization for production and marketing that generates low economic profitability, the marketing controlled by the intermediary which eliminates the sustainable 
local value chain of honey.

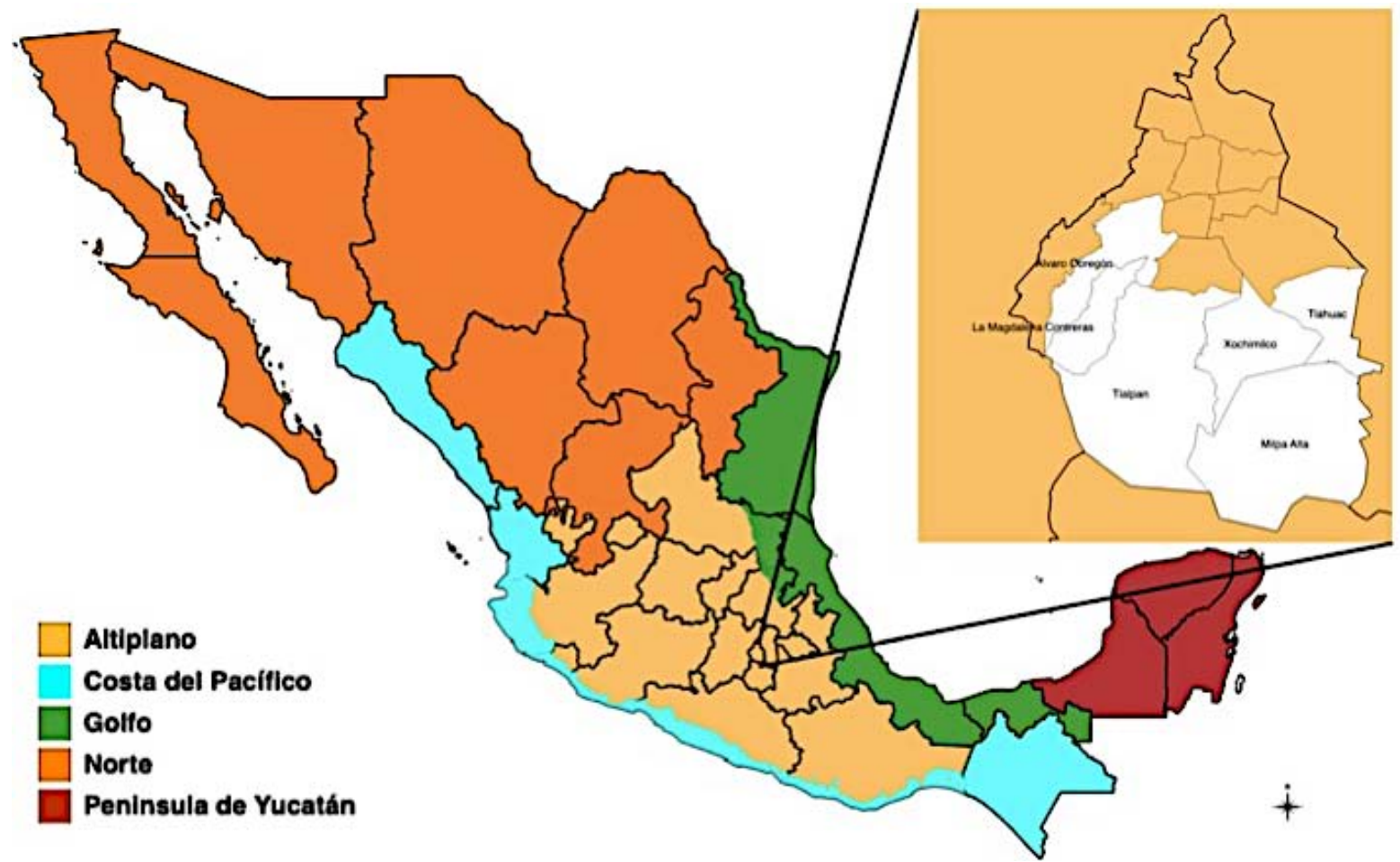

Figure 1. The six municipalities in Mexico City where almost 4,000 hives are located, from General Livestock Coordination of the Secretariat of Rural Development (SADER).

Additionally, honey in Mexico City is a frequent target of adulteration through inappropriate production and storage practices to reduce it cost, mainly. This affects the markets of honey because the price is lower than the non-adulterated honey. Also, this affects consumer's health because they are not informed about the quality of the honey and purchase it thinking that it is of high quality. Figure 2 shows a selling point of adulterated honey on the street in Mexico City. Much effort thus, now is directed to fight the adulteration problem [4]. According to the European Union legislation the physicochemical analysis is one method that requires highly skilled personnel [4,5]. Table 1 indicates the physicochemical characteristics of two adulterated honey samples purchased at different selling points on the street in Mexico City. A considerable change in viscosity has been observed in honey samples with more than $50 \%$ of a saturated solution of sugar. Also, lactone value of two samples was out of the Codex Alimentations, 2001 limit.

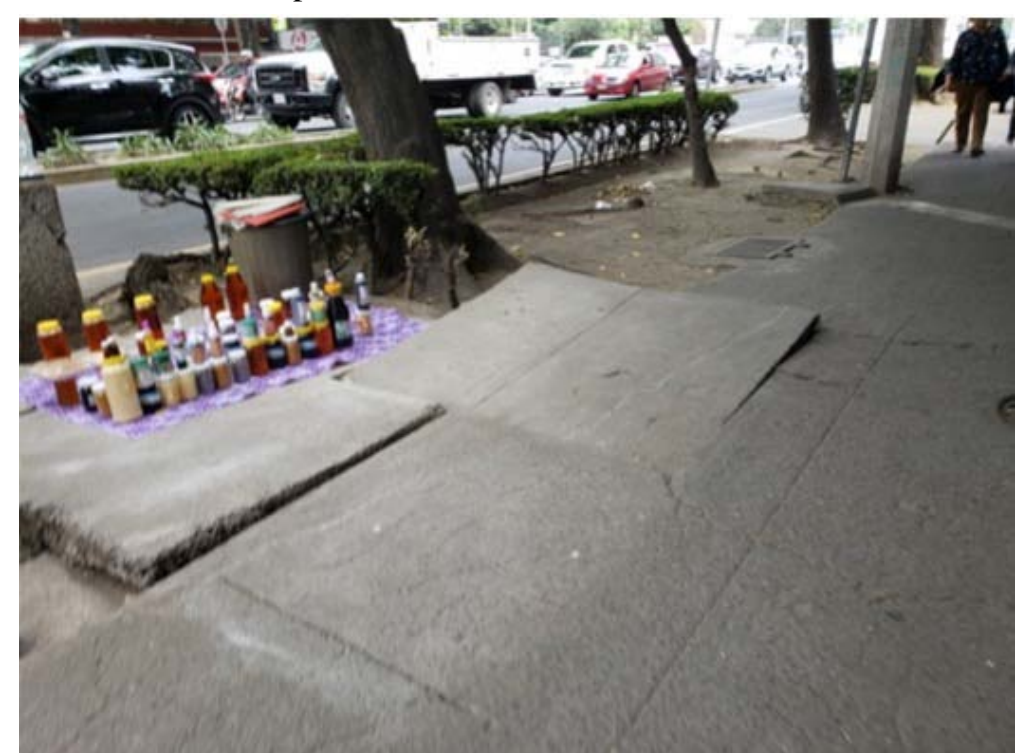

Figure 2. A selling point of adulterated honey in Mexico City on street. 
Table 1. Physicochemical characteristics of two adulterated honey samples

\begin{tabular}{cccc}
\hline & Adulterated honey sample 1 & Adulterated honey sample 2 & Official Mexican Standard \\
\hline Color (mm Pfund) & & & $\begin{array}{c}\text { White water } \\
\text { Extra white } \\
\text { White }\end{array}$ \\
& Extra light amber & 53 & $\begin{array}{c}\text { Extra light amber } \\
\text { Light amber } \\
\text { Amber }\end{array}$ \\
Dater content (\%) & & Light amber & Dark amber \\
pH & 18.7 & 20 maximum [6] \\
Electrical conductivity (mS/cm) & 0.09 & 18 & 0.8 maximum[6] \\
Total acidity (meq/kg) & 4.19 & 0.04 & $3.4-6.1[7]$ \\
Free acidity (meq/kg) & 10.5 & 4.67 & 40 maximum [6] \\
Lactona (meq/kg) & 10.5 & 7 & $<50$ [7] \\
Reducing sugars (\% g/100g) & 0 & 7 & $2.8-11.5[7]$ \\
\hline
\end{tabular}

At national level, in Mexico there are different organization and associative figures that group beekeepers nationally as well as locally. According to [8], Mexican beekeepers are registered in 508 livestock associations specialized in beekeeping and 110 associations of other types. A specific kind of social organization for Mexican Beekeepers is the cooperative society figure, which is formed by persons based on common interests and on the principles of solidarity, self-effort and mutual aid, with the purpose of satisfying individual and collective needs, through the performance of economic activities of production, distribution and consumption of goods and services related with beekeeping.

Cooperatives generally have long been used as an engine for rural development facilitating marketing, agricultural activity and their social benefits [9]. They are highly preferred because of its advantages, such as shared resources, experience and skills, aggregation and gaining bargaining power [10] most of which provide a solution to most of the rural business operation challenges. In Mexico City, there are three cooperative societies specialized in beekeeping [11]: BiomielArtesanal SC de RL, ApiarioAtotolco SC de RL de CV, and ConstruirenRaices SC de RL de CV. These cooperatives have increased diversity in the transformation process adding value to the beekeeping products in order to attend the necessities of the final consumer. In the first case, the innovation in beauty products has been the business driver; while in the second case, the cultural and environmental innovations have been the business pillars; in the third case, the innovation in food and drinking products based on honey has been the key condition for the continued success of the business. Unfortunately, Mexican consumers do not recognize the ancestral value of beekeeping neither the importance of it to achieve sustainable development.

The main purpose of this chapter is to develop a model of socio-cultural innovation, which revalue the beekeeping of Mexico City as a traditional activity of ecological importance and improve its position as a sustainable productive activity of honey with the participation of local cooperatives societies. We consider that the main results of this study contribute to the sustainable development of beekeeping in Mexico City.

The outline of this chapter is as follows. Section 2 presents the beekeeping cooperative societies located in Mexico City. Section 3 describes the feasible opportunities of marketing of honey and its derivates in the context of Mexico City that leads to revalue the beekeeping as a traditional activity of ecological importance. Section 4 analyses the main characteristics of sustainable honey production models. In Section 5, a socio-cultural innovation model is characterized and integrated into the cooperative business model for sustaining beekeeping. This chapter ends with concluding remarks in Section 6 .

\section{Beekeeping Cooperative Societies Located in Mexico City}

\subsection{ConstruirenRaices S.C. de R.L. de C.V.}

In 2014, it was established as a cooperative society after transitioning as a family business and working the land for more than three generations. Its apiaries are located in the municipality of Milpa Alta (see Figure 3). Since 2007, it has been certified in Good Practices for Honey Production. It is important to note that this cooperative, with its agroecological production, also offers lessons in food self-sufficiency. Its transformation and value addition process are based on the collaboration with universities and the innovation in food and drink products whose main ingredient is the honey produced in the apiaries. The products are sold mainly in the Tlalpan organic market on weekends. 


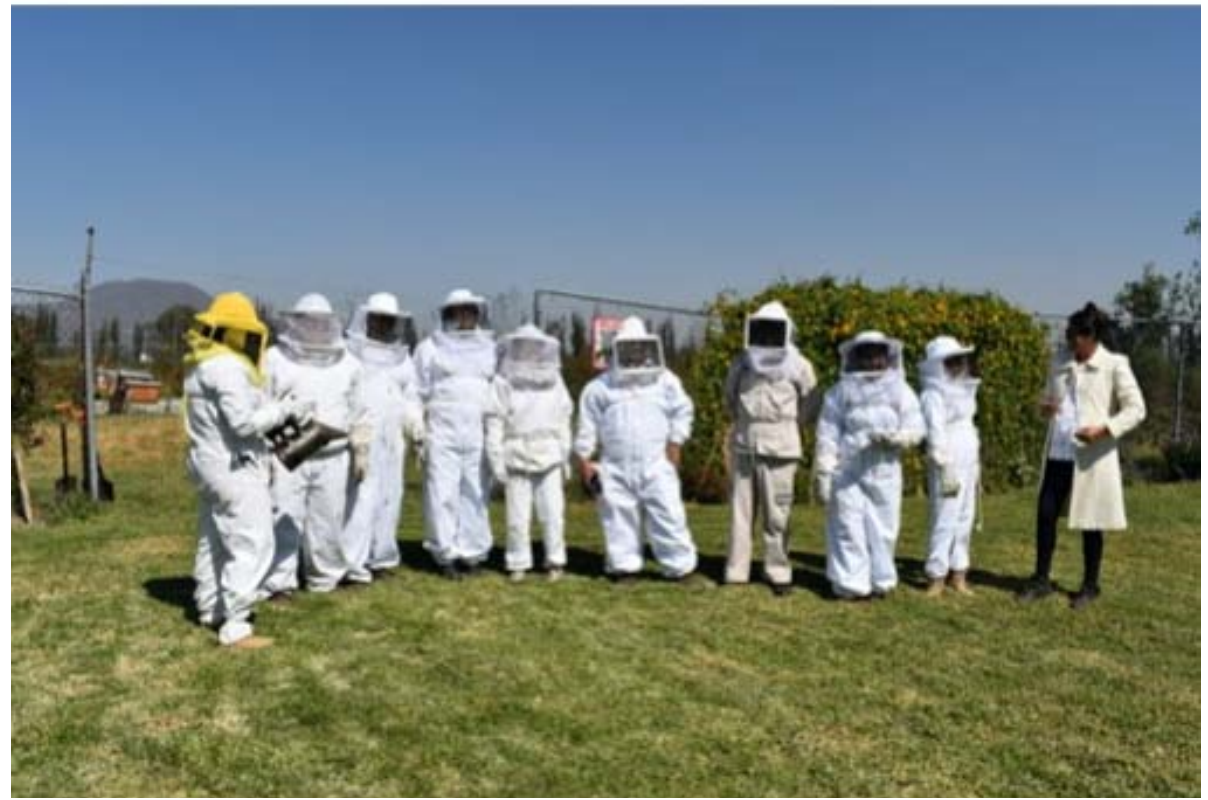

Figure 3. Technical team with the owner of cooperative society ApiarioAtotolco S.C de R.L de C.V.

\subsection{ApiarioAtotolco S.C. de R. L. de C.V.}

It is a cooperative society of beekeepers from the municipality of Tláhuac. The cooperative had the need to withdraw from its original physical space due to the growth of the urban area in Mexico City, relocating the apiaries to the Chinampas of Tláhuac, for which reason it has the mission of preserving these Chinampas as natural heritage. A Chinampa is a small piece of land built on a lake by superimposing a layer of stone, another of reeds and another of soil, in which vegetables and flowers are grown; in former times it was the culture system of the lacustrine zone of the valley of Mexico (see Figure 4). ApiarioAtotolco produces honey and transform it into products such as granola, cream, shampoo and soaps. Its transformation and value addition process is based on cultural and environmental innovation. The products are sold mainly in cultural festivals, local store, fairs, cooperativism events, and social economy festivals.

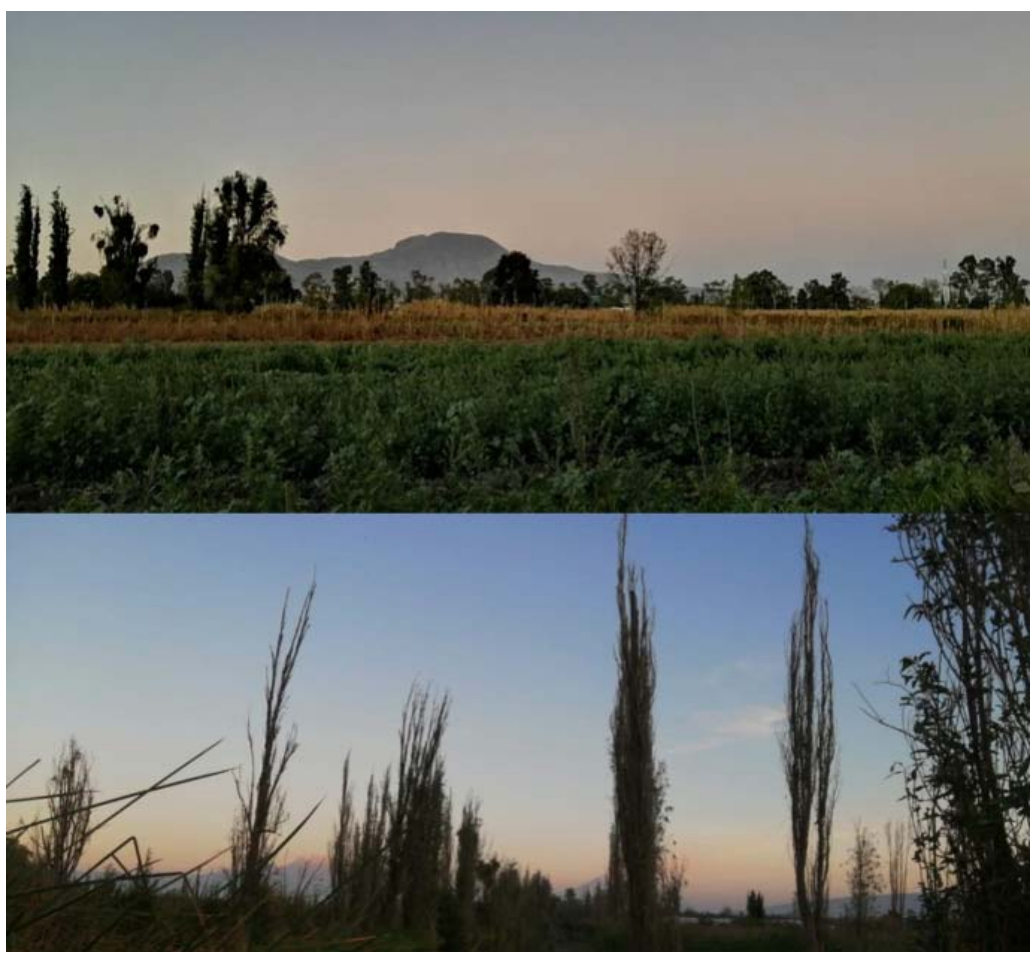

Figure 4. The natural environment of Chinampas in municipality of Tláhuac. 


\subsection{BiomielArtesanal S.C. de R.L.}

It is a family cooperative that seeks to provide natural products that are friendly to the environment; also contributes for the care in the hygiene, health care and beauty of people, providing the highest quality. The transformation and value addition process are based on innovative beauty products whose main ingredient is the honey produced in the apiaries. The products are sold mainly in cooperative events, fairs, and national and international sustainable projects. However, this cooperative has been supported by Mexican federal government to export its products to United States of America.

\section{Feasible Opportunities of Marketing of Honey and Its Derivates in Mexico City}

In [12], an interesting literature review about the various factors that influence consumers when purchasing honey is presented. According to [12], in Asia the decision is often habitual and dictated by knowledge of the honey's value. For example: medical conditions, quality of the product, brand reputation, and pricing. In Saudi Arabia, the major motivations for consuming honey are its medicinal and nutritional values. While in US consumers are willing to pay substantial premiums for honey based on form, container, brand and, in particular, unique monofloral sources.

Despite the wide domestic production, consumption of honey (natural or as an ingredient in pastries, desserts, bread, yogurt, and beverages) is relatively low in Mexico [13]. In fact, Mexicans are not used to consume this product frequently. Consumption levels have been slowly growing since 2012 and are projected to further rise in the coming years [14]. Per capita consumption, on the contrary, was 190 grams per capita during the nineties, increasing to 320 grams in 2010 [3] and is set to remain stable at approximately $0.1 \mathrm{~kg}$ over the next few years, driven by health-conscious consumers [13].

Nonetheless, an increasing number of Mexicans has started to purchase honey as a healthier alternative to sugar that can have a positive impact on the immune system, although this is not the case of price-sensitive consumers [14]. Nowadays, it seeks to increase this consumption through new forms of transformation and industrialization, as well as novel presentations.

As outlined in [13], in Mexico distribution of spreads, including honey, entirely relies on store-based retailing, specifically grocery retailers (95.4\%). Of these, as is showed in Figure 5, in 2017, over half were traditional grocery retailers, especially independent small grocers, while $44.9 \%$ were modern grocery retailers, mostly discounters (15.4\%), hypermarkets (12.4\%), and supermarkets (12.3\%).

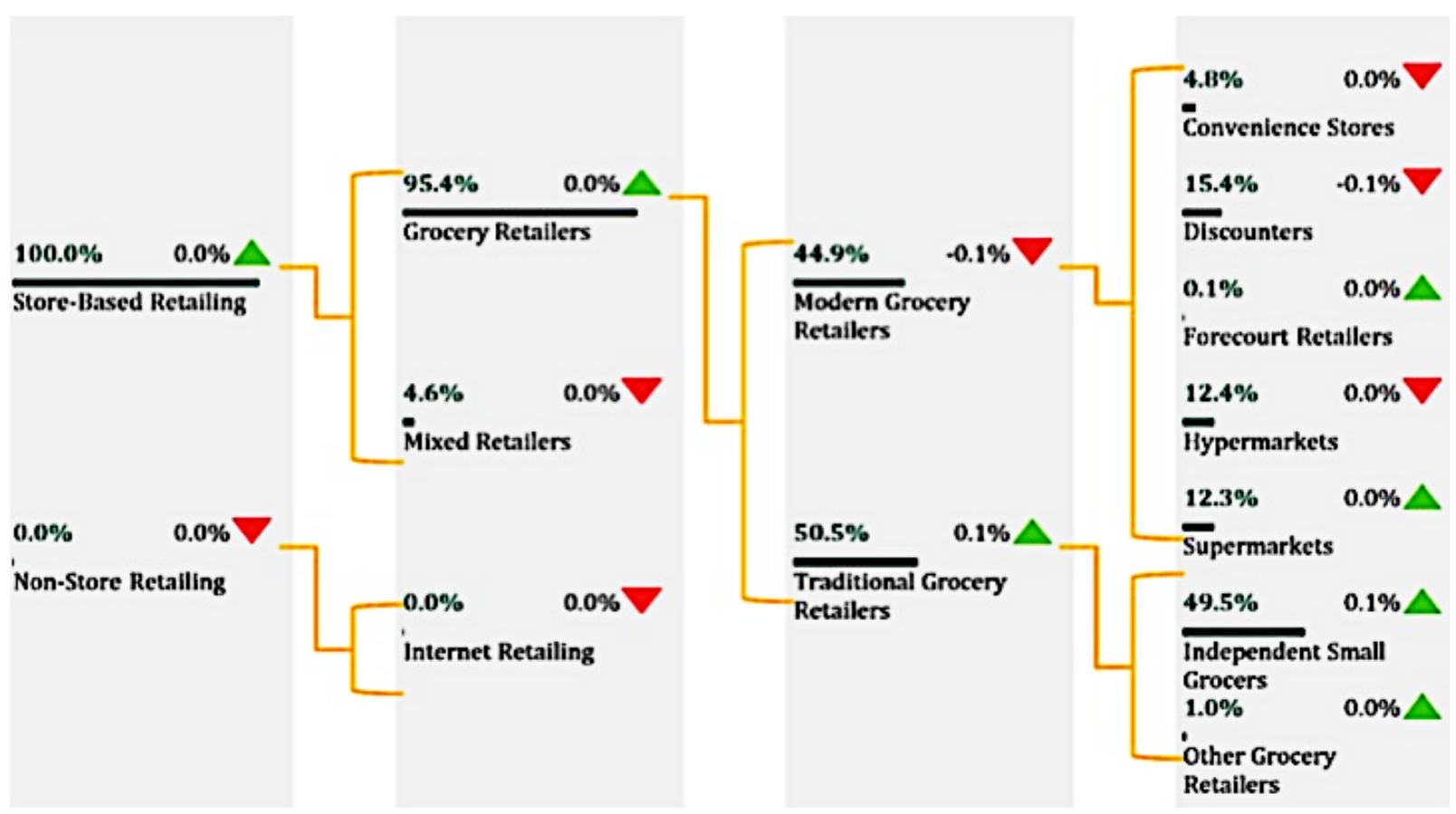

Figure 5. Distribution channels overview of spreads (including honey) in Mexico for year 2017 [13].

\section{Sustainable Honey Production Models}

As is suggested by [15], from the value chain perspective, honey production includes the purchasing of materials needed to produce honey (queen and bees, the supplement feeding, the beeswax) and the installation of equipment of 
land (such as hive equipment) (see Figure 6). This process is concluded when the honey is ready in honeycombs and the blossom season is over [15]. The beehives and the hive frames are important factors in the living environment of honeybees, and it is essential to maintain the health of colonies [16]. It is necessary to keep beehives clean to prevent apicultural product contamination (see Figure 7). It is recommended not to use old beehives that have existed for 5 years or longer [16].

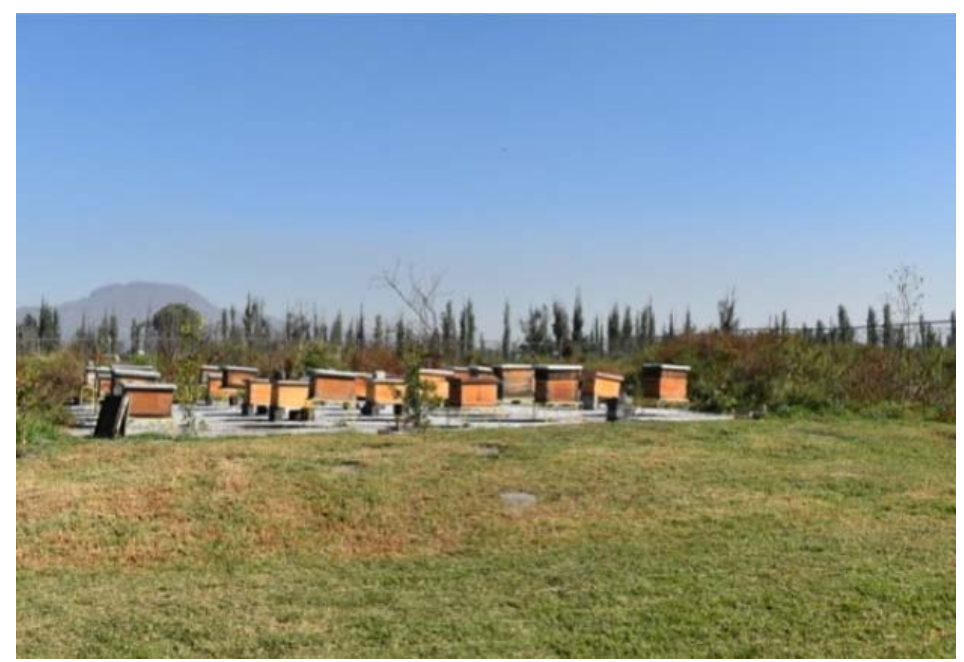

Figure 6. The installation of an apiary.

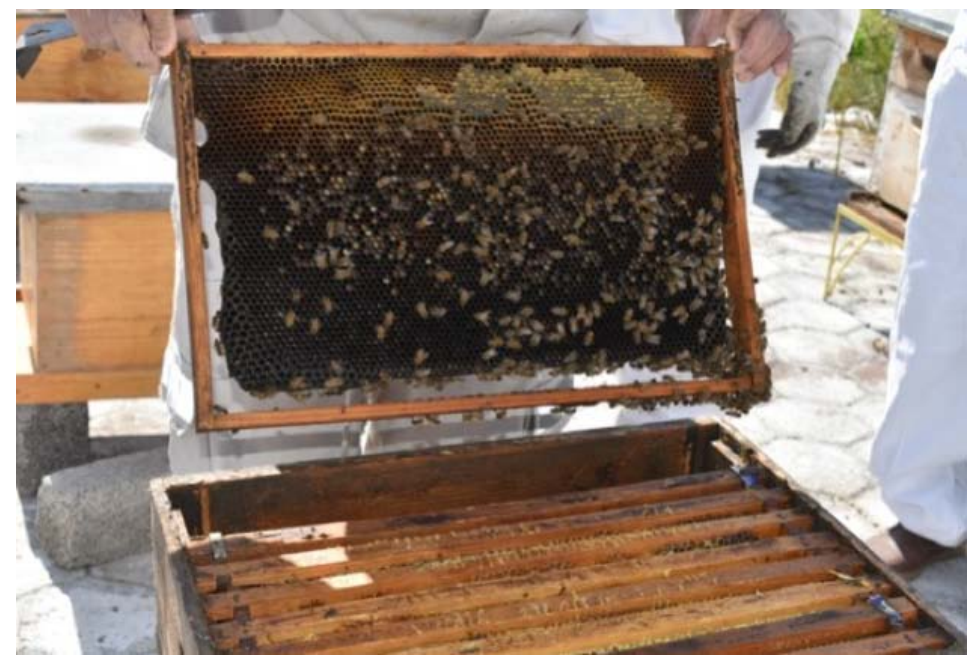

Figure 7. Hive assembly and a swarm of bees working on honeycombs.

As indicated in [17], the honey production process, like other food production processes, is sensitive to physical, chemical and biological contaminations that can cause harm to consumers, therefore it is necessary to apply strategies to reduce risks. The strategies can be derived from different manuals of good practices for the production, manufacturing, Risk Analysis Systems and Control of Critical Points, as well as the National Program of Safety and Quality of Honey, these strategies must be applied to each step of the honey production process, which will guarantee the quality of the final product [17].

Productivity of beekeeping is a measure of honey yield per colony/beehive that affects the profitability of beekeeping enterprises [18]. Colony strength, types of hives used, age of the queen, swarming of colonies and honeybee management practice are major factors influencing the profitability of beekeeping business [19]. For productive bee production, it is necessary to apply modern technologies and production methods of beekeeping as well as to have modern and appropriate equipment to increase the chance of success [20].

On the other hand, sustainability is considered the Triple Bottom Line of three dimensions: economic, environmental and social [21]. The important role covered by the three dimensions of sustainability has been discussed in the UN Sustainable Development Goals (SDGs) 2015-2030 aiming to balance and encourage the application of these dimensions over the next years [22]. When the cultural aspect is added to sustainability, the concept of sustainable engineering emerges [23]. Furthermore, sustainable engineering includes technical approaches from structural and process engi- 
neering [23], as well as ecosystem approaches from bio-and ecological engineering. Sustainability also is considered a fundamental pillar in ensuring the balanced socio-economic development of the rural space [24]. In fact, honey production provides additional income for many poor communities, creating new opportunities in rural areas, and improving the living conditions of many families. Therefore, a sustainable honey production model includes the three dimensions of sustainability in all its production methods: economic, environmental and social, and applies modern technologies to guarantee the quality of honey that helps to improve its competitive position.

\section{The Cooperative Business Model for Sustaining Beekeeping}

The cooperative structure is among the highly suggested and preferred business models by government [25]. At international level different modes of cooperative are recognized: community-based enterprises /organizations (CBO), regional, national, and crop/produce-based cooperatives [26].

At national level, in Mexico the General Law of Cooperative Societies (GLCS), with the latest reform published in DOF 19-01-2018, includes the definition of a cooperative society as a form of social organization made up of individuals based on common interests and on the principles of solidarity, self-effort and mutual aid, with the purpose of satisfying individual and collective needs, through the performance of economic activities of production, distribution and consumption of goods and services. The GLCS recognizes three types of cooperatives in Mexico: consumers of goods and/or services, and producers of goods and/or services, and savings and loan. In the Article 6, the GLCS indicates that a cooperative societies must observe the following principles in their operation: freedom of association and voluntary withdrawal of members; democratic administration; limitation of interests to some contributions of the partners if so agreed; distribution of the returns in proportion to the participation of the partners; promotion of cooperative education and education in the solidarity economy; participation in cooperative integration; respect for the individual right of the members to belong to any political party or religious association, and promotion of ecological culture. The cooperative business model requires a collective of other individual responsibilities among members that could be achieve through a combination of actions and procedures such as decisions, mutual agreements, and voting, as well as need for increased dedication and honesty [26]. The cooperative business model for sustainable beekeeping includes the three dimensions of sustainability in all its production methods: economic, environmental and social, and applies modern technologies to guarantee the quality of honey that helps to improve its competitive strategy.

On the other hand, the socio-cultural innovation of cooperatives for sustainable beekeeping is a process of gradual change through action research in localized territories, which involves:

- A set of beekeepers associated in cooperatives and social actors, based on their own interests, missions and capacities, who participate in specific activities (scientific, technological, environmental, cultural, organizational, financial or commercial) in the sustainable beekeeping value chain.

- The orientation is not only to participate for solving problems associated with sustainable beekeeping (for example the lack of biodiversity) and its value chain and promoting the cultural rescue and incorporation of traditional beekeeping knowledge, but to generate social learning that promotes structural transformations and the autonomy of cooperatives to preserve their productive diversity and to strengthen their capacity for managing sustainable beekeeping.

- The use of dialogue as the means of social learning in and outside of cooperatives, based on tools and instruments such as technical and scientific information systems and computational platforms for collaborative work.

Such factors facilitate the development of learning communities for the socio-cultural innovation inside the cooperatives. Finally, to carry out the socio-cultural innovation of cooperatives of beekeepers it is necessary to use a transdisciplinary methodological approach, to take into account the traditional knowledge generated by resolving local sustainability problems that affects beekeeping, respect the worldview of the municipalities where beekeeping develops and to incorporate information technologies to promote the cultural memory of beekeepers regarding sustainable beekeeping and to use technological adoption models for activities deemed relevant in the value chain of honey and products derived.

\section{Conclusions}

In Mexico City, despite the wide domestic honey production (over 70 tons annually), per capita consumption is relatively low, approximately $0.1 \mathrm{~kg}$. Additionally, honey in Mexico City is a frequent target of adulteration to reduce it cost so consumers pay less affecting the value chain of honey. As the beekeeping is part of the local food culture, a model of socio-cultural innovation, was presented in order to revalue the beekeeping of Mexico City as a traditional activity of ecological importance, with the participation of local cooperatives societies. The orientation was focus in the capacity of cooperative societies and their learning communities to manage sustainable beekeeping. We consider that the main results of this study contribute to the sustainable development of beekeeping in Mexico City considering the three dimensions: social, economic and environmental. 


\section{Acknowledgments}

This work was supported by UNAM-PAPIIT TA 101219. Authors are thankful to the three cooperative societies: CepraMiel SC de RL de CV, ApiarioAtotolco SC de RL de CV, ConstruirenRaices SC de RL de CV., from this study that generously provided their time during the field work. Authors appreciate Bee Team, El Colegio de la Frontera Sur, for its help in this work.

\section{References}

[1] Allsopp, M. H., de Lange, W. J., Veldtman, R. (2008). Valuing insect pollination services with cost of replacement. PLoS One. 2008, 3: e3128. DOI: 10.1371/journal.pone.0003128

[2] Kohsaka, R., Sun Park, M., Uchiyama, Y. (2017). Beekeeping and honey production in Japan and South Korea: past and present. Journal of Ethnic Foods, 2017, 4: 72-79.

[3] Contreras-Escareño, F., Echazarreta, C. M., Pérez-Armendáriz, B., Cavazos Arroyo, J., Macías-Macías, J. O., and Tapia-González, J. M. (May 20th 2016). Beekeeping in Jalisco, México, Beekeeping and Bee Conservation. In: Dechechi Chambo E, editor. Advances in Research, IntechOpen, DOI: 10.5772/62506. Available from: https://www.intechopen.com/books/ beekeeping-and-bee-conservation-advances-in-research/beekeeping-in-jalisco-m-xico.

[4] Dramicanin, T., LenhardtAckovic, L., Zekovic, I., Dramicanin, M. D. (2018). Detection of adulterated honey by fluorescence excitation-emission matrices. Journal of Spectroscopy. 2018, Article ID 8395212. DOI: https://doi.org/10.1155/2018/8395212.

[5] Piazza, M. G., Accorti, M., and Oddo, L. P. (1991). Electrical con-ductivity, ash, colour and specific rotatory power in Italian unifloral honeys. Apicoltura. 1991, 7, 51-63.

[6] PROYECTO de Norma Oficial Mexicana PROY -NOM-004-SAG/GAN-2018, Producción de miel y especificaciones , DOF, 2018.

[7] Codex Alimentations. Draft revised standard for standard for honey (at step 10 of the Codex procedure). Alinorm. 2001, 01 (25): 19-26.

[8] Atlas Nacional de las Abejas y DerivadosApícolas 2017. (2020). https://atlasapi2019.github.io/index.html.

[9] Musinguzi, P., Skovmand Bosselmann, A., Pouliot, M. (2018). Livelihoods-conservation initiatives: Evidence of socio-economic impacts from organic honey production in Mwingi, Eastern Kenya. Forest Policy and Economics. 2018, 97: 132-145.

[10] Tutuba, N., Msamula, J., Thundui, H. (2019). Business model innovation for sustainable beekeeping in Tanzania: A content analysis approach. 2019, 19(1), 74-88.

[11] Catálogo de Cooperativas de la Ciudad de México. (2019). http://www.cooperativas.cdmx.gob.mx/styfe/coop100/catalogo.php.

[12] Cosmina, M., Gallenti, G., Marangon, F., Troiano, S. (2016). Attitudes toward honey among Italian consumers: A choice experiment approach. Appetite. 2016, 99: 52-58.

[13] European Union. (2019). Consumers, Health, Agriculture and Food Executive Agencya (Chafea). The Food and Bevetage Market Entry Handbook: Mexico. European Union.

[14] Euromonitor International: Packaged Food. (2018).

[15] Kouchner, C., Ferrus, C., Blanchard, S., Decourtye, A., Basso, B., Le Conte, Y., Tchamitchian M. (2019). Bee farming system sustainability: An assessment framework in metropolitan France. Agricultural Systems. 2019, 176: 102653.

[16] Casofrances. (n.d.).

[17] Ramos-Díaz, A., Cano-Sosa, J., Uc-Várguez, A., García-Muñoz, Y., Koyoc-Canché, A. (2016). Etapas de la producción de miel. EnProducción y comercialización de miel y sus derivadosen México: desafíos y oportunidades. In Ramos Díaz A L, Pacheco López N A, editoras. CiatejConacyt. 2016.

[18] Jones, R. (2004). European beekeeping in the 21st century: strengths, weaknesses, opportunities, threat. Bee World. 2004, 77-80.

[19] Al-Ghamdi, A. A., Adgaba, N., H. Herab A., Ansari, M. (2017). Comparative analysis of profitability of honey production using traditional and box hives. Saudi Journal of Biological Sciences. 2017, 4: 1075-1080.

[20] Cejvanovic, F., Grgic, Z., Maksimovic, A., Bicanic, D. (2011). Assumptions of economic model for sustainable productions of beekeeping in the Bosnia and Hercegovina. Journal of Agricultural Science and Technology. 2011, 5(4).

[21] Klöpffer, W. (2008). Life cycle sustainability assessment of products. Int. J. Life Cycle Assess. 2008, 13(2): 89-95.

[22] D`Eusanio, M., Serreli, M., Zamagni, A., Petti, L. (2018). Assesment of social dimension of a jar of honey: A methodological outline. Journal of Cleaner Production. 2018, 199: 503-517.

[23] Halbe, J., Adamowski, J., Bannet, E. M., Pahl-Wostl, C. (2014). Khosrow Farahbakhsh. Functional organization analysis for the design of sustainable engineering systems. Ecological Engineering. 2014, 73: 80-91. 
[24] Mioara, B., Irina Teodora, M. (2015). The implication of international cooperation in the sustainable valorization of rural touristic heritage. Procedia-Social and Behavioral Sciences. 2015, 188: 222-229.

[25] Sizya, M. J. (2001). The Role Co-Operatives Play in Poverty Reduction in Tanzania. In: The United Nations. In Observance of the International Day for the Eradication of Poverty.

[26] Tutuba, N. B., Msamula, J. S., and Tundui, H. P. (2019). Business Model Innovation for Sustainable Beekeeping in Tanzania: A Content Analysis Approach. American Journal of Management. 2019, 19(1). https://doi.org/10.33423/ajm.v19i1.1340. 